\title{
Combat and Herbicide Exposures in Vietnam among a Sample of American Legionnaires ${ }^{1}$
}

\author{
Steven D. Stellman, ${ }^{* 2}$ Jeanne Mager Stellman, $\dagger$ and \\ JOHN F. SOMMER, JR.† \\ *Department of Epidemiology and Statistics, American Cancer Society, New York, New York; \\ $\uparrow$ School of Public Health, Columbia University; and $\ddagger$ National Veterans Affairs and Rehabilitation \\ Commission, The American Legion, Washington, D.C.
}

Received November 2, 1987

\begin{abstract}
A cross-sectional survey of 6810 randomly selected members of The American Legion in six states who served in the U.S. Armed Forces during the Vietnam Era was conducted by a mailed questionnaire. Combat stress was evaluated by a previously validated eight-item scale. Exposure to Agent Orange and other herbicides was estimated via exposure probability index previously developed by the authors which uses an algorithm based on the combined Air Force and Joint Services HERBS files of spray data. Two-fifths of the men had served in Southeast Asia, generally at the same time during which the major proportion of herbicides were used; the remaining subjects served elsewhere. Both combat and Agent Orange exposure exhibited distinct, meaningful distributions among Vietnam veterans with service in Southeast Asia and were also correlated with each other $(r=0.24)$. Our analysis demonstrates conclusively that mere presence in Vietnam cannot be used as a proxy for exposure to Agent Orange. Categorization of Vietnam veterans according to herbicide exposure can be successfully accomplished, based on an existing detailed herbicide application data base. This analysis, together with the consistent dose-related results obtained in this series of papers on health and behavioral effects, demonstrates the utility of questionnaire-derived herbicide and combat exposure measures for epidemiologic study of Vietnam veterans. 1988 Academic Press, Inc.
\end{abstract}

\section{INTRODUCTION}

During the years 1964 to 1975 , approximately 9 million people served in the armed forces of the United States. Estimates of the number of soldiers who served in Southeast Asia generally range between $32 \%$, or about 3 million, and $48 \%$, or about 4.4 million (Fischer et al., 1980) of these troops. About 56,000 soldiers died as direct casualties of the Vietnam conflict. More than 300,000 troops were wounded.

Although the Vietnam Era officially ended in 1975, the human aftermath of that war, as of any war, continued in the form of psychological and physical effects of combat on the returning veterans, on their families, and, indeed, on the nation. Public discussion and memory, which eventually relegated the wartime experiences of veterans of other wars to a few memorial days each year, cannot free themselves of Vietnam. The Vietnam conflict seems to grow on the mind and

\footnotetext{
${ }^{1}$ Address reprint requests to Foundation for Worker, Veteran and Environmental Health, Inc., 117 St. Johns Place, Brooklyn, NY 11217.

${ }^{2}$ Present address: New York City Department of Health, New York, NY 10013.
} 
conscience of the nation, spurring on Congressional hearings, commissioned studies and reports, state commissions, and the like. While war films from other conflicts become curious, dated relics of another day, new films about Vietnam continue to be made and continue to draw crowds and win awards and publicity, almost a decade and a half after the fighting has ended. The overall issue of "healing from the war" is still current in 1988 (see, for example, Egendorf, 1985; Boulanger and Kadushin, 1986).

Much public discussion has focused on the health and well-being of the veterans who fought in Vietnam. Foremost in the discussion has been the fear that powerful herbicidal agents, like Agent Orange, used to defoliate many of Vietnam's dense jungles, may have induced health-threatening effects in American soldiers who were exposed to it (Gough, 1986). Another major public health issue has been the possible long-term psychological effects of the aftermath of heavy combat exposure, technically referred to as post-traumatic stress disorder, or PTSD (Boulanger and Kadushin, 1986).

The American Legion is the largest of the veterans' service organizations chartered by the U.S. Congress, with approximately 700,000 Vietnam Era veterans among its members, which constitutes a meaningful percentage of those approximately 3 to 4 million men who served in the military during that Era. The Legion undertook the sponsorship of this study in order to answer many questions concerning the health and well-being of its Vietnam Era members.

The specific aims of the study were to select a random sample of Vietnam veterans from among the membership of The American Legion, approximately half with service in Southeast Asia and half without, and to obtain and analyze demographic information on them. Employing herbicide exposure techniques we had previously developed (Stellman and Stellman, 1986), we sought to characterize the respondents' exposure to herbicides, as well as their exposure to traumatic military experiences during their time of service. The study sought to obtain and analyze information on the personal, reproductive, family, and mental health of the veterans, and on health behaviors, such as smoking, drinking, and using drugs, and to determine the extent to which these behaviors and outcomes varied with respect to exposure to combat and herbicides. We also investigated veterans' attitudes toward and perceptions of the Veterans Administration and their actual experiences with its facilities and programs, since this agency is charged with providing for the health and well-being of American veterans.

This paper, the first in a series of five, provides an analysis of the patterns of exposure of American Legionnaires to various levels of combat and herbicides. Three of the subsequent papers treat the effects of these two factors on social and behavioral outcomes (Stellman et al., 1988a); physical and reproductive health (Stellman et al., 1988b); and post-traumatic stress disorder (Snow et al., 1988). A final paper examines the experience of veterans at Veterans Administration health facilities (Stellman et al., 1988c).

Until recently, quantitative data on herbicide application in Vietnam were available only for Air Force operations in the form of the so-called HERBS tape, which gave detailed information on 6475 spray missions and dispersal of about 17.5 million gallons of herbicides. We have previously published a summary of those 
operations, according to herbicide type, mission purpose, and calendar period (Stellman and Stellman, 1986). Using newly available information on the use of herbicides by all services (U.S. Army Joint Services Environmental Support Group, 1986), we provide here an updated analysis of the use of defoliants during the conflict period. The update includes 1507 newly documented spray missions, involving dispersal of 1.6 million gallons of herbicides, which represents about a 9\% increase over data previously available on the Air Force HERBS tape. These data were kindly furnished by the U.S. Army and Joint Services Environmental Support Group, who have been undertaking an exhaustive review of military spraying during the Vietnam Era.

Exposure to combat stress and to herbicides is a central feature of this study. The purpose of this paper is to describe the study design, to explain the exposure evaluation methodology, and to describe the distribution of these two factors, both separately and jointly, among the study population, as a preliminary but necessary step toward assessment of health, behavioral, and social outcomes in the papers that follow.

\section{MATERIALS AND METHODS}

\section{Design of Study}

The study has a cross-sectional design in which various outcome measures are compared between two groups of veterans: those who served in Southeast Asia and those who served elsewhere; it also examines differences between men who experienced different levels of combat and herbicides in Southeast Asia. The study is restricted to male American Legion members on the membership rolls as of October 15, 1983, whose posts are located anywhere in six states: Colorado, Ohio, Maryland, Pennsylvania, Indiana, and Minnesota. Analysis is based on a mailed, self-administered questionnaire which was distributed to a random sample of Vietnam Era veterans selected from the membership roster. Procedures were identical in each of the six states.

Since the Legion did not keep records of which war a member had served in, we were faced with the task of differentiating Vietnam Era veterans from other veterans. A tape was prepared which contained the names and addresses of all American Legion members as of October 1983, excluding those with 20 or more years of continuous membership, since practically all such persons served only in previous wars and were therefore ineligible for this study. The tape was passed and one-seventh of the records were extracted at random. A returnable postcard was mailed to each member with a request that he check off whether he was a Vietnam Era veteran. For each postcard returned, an entry was made in the computerized file. The names of people who had returned their postcards were removed from the file and the remainder of the file was sorted by Post. A list of these names was sent to each Post Adjutant, who was asked to identify Vietnam Era members. This method led to the classification of additional men as to which war they had served in. This identification process was designed to eliminate non-Vietnam era veterans. It was not a process whereby a veteran selected himself into the study by filling out a postcard. 
The lists at this point contained, in aggregate, all members of the one-seventh sample who either (a) had been identified by postcard or Post Adjutant as Vietnam Era, or (b) whose Era was as yet unknown.

In each state, "Captain organizers" were trained to recruit "volunteer researchers" to assist in identification of Legionnaires by area of military service. The aggregate lists of potential subjects were divided up among these researchers, each of whom participated in a 1-day training session conducted by two of us (J.M.S. and J.F.S.). These sessions emphasized that the only role of the Legionnaire volunteers was to determine service location and to establish personal contact with potential enrollees, in order to maximize the ultimate participation rate. All Legionnaires selected through our random process, after identification as to service area, received questionnaires, even if they indicated to the volunteers that they did not wish to participate. Each researcher thereby received a list of about 200 potential subjects, some (but not all) of whom had been previously identified as Vietnam Era. The researchers were given the task of contacting all persons on the lists, in order to determine which people on the list not already classified were Vietnam Era veterans and which were not. In addition, since our design was to have approximately half of our population with service in Southeast Asia and half without, the volunteer asked where the veteran had served. Each volunteer was given a goal of identifying 15 Southeast Asia and 15 non-Southeast Asia veterans. If the veteran identified himself as a Vietnam Era veteran and was within the volunteer's quota, he was acquainted with the study, told he would receive a questionnaire shortly, and strongly urged to fill it out. Questionnaires were sent to all identified Vietnam Era veterans, regardless of whether they were cooperative on the telephone inquiry. Since less than one-half of all Vietnam Era veterans actually served in Southeast Asia, it was usually easier to find non-Southeast Asia subjects. The final fraction of study subjects who served in Southeast Asia was $42.0 \%$. It is to be emphasized that the researchers' job was primarily that of identifying the target study population, not recruitment of subjects. Once a member was identified as Vietnam Era, he was regarded as a study subject regardless of his expressed willingness to complete a questionnaire.

The ratio of researchers to subjects was determined by a pretest conducted by Dr. Gloria Gordon, using American Legionnaire volunteers in South Dakota. The membership tape sampling fraction of one-seventh was based upon these pretest results, which yielded estimates of Vietnam Era membership and response rates, and was further set to yield numbers of subjects in various exposure categories to provide ample statistical power for comparisons of interest.

\section{Characterization of Herbicide Exposure}

Estimation of exposure to herbicides such as Agent Orange in Southeast Asia is without doubt the most difficult component of the entire study. We have recently developed an exposure estimation methodology (Stellman and Stellman, 1986) which uses a probabilistic exposure index based upon the Department of Defense's HERBS tape and supplementary files developed by the U.S. Army Joint Services and Environmental Support Group. This collection of records contains information on 9495 individual spray missions carried out in Vietnam, each with 
the date, chemical agent (Orange, White, Blue, etc.), number of gallons, detailed coordinates of application, and purpose of mission (defoliation, crop destruction, etc.)

Statistical analysis of the tape was carried out to characterize the total gallonage of each type of agent used, the dates on which the missions occurred and their purposes.

One section of the questionnaire contained a list of about 100 places in South Vietnam where major troop activity was known to have been centered. Each subject who served in Southeast Asia was asked to give dates he had served at each of these places.

We constructed an index which matches the 23,267 spray coordinates contained on the combined Air Force HERBS tape and U.S. Army Joint Services Environmental Support Group Services HERBS tape with the information supplied on the study cohort questionnaires. The methodology is explained more fully elsewhere (Stellman and Stellman, 1986). We present only a brief overview of the method here. For each of the three major herbicides (Orange, White, Blue), an index of the form:

$$
E_{3}=C_{0} \sum_{i j}\left(1 / D_{i j}\right) \int_{t_{1, i j}}^{t_{2, i j}} e^{-\lambda t} d t
$$

was computed for that subject. In the equation, $C_{\mathrm{o}}$ is a constant and $\lambda$ is a postulated decay constant (ln 2/half-life) for an "active" ingredient, such as TCDD, taken here to be 1 year (DiDomenico et al., 1980; Young et al., 1976; Kearny et al., 1972). Choice of a first order rate law is a conservative one. The choice of a 1-year half-life is somewhat arbitrary, but it is consistent with a number of environmental measurements. Our calculations show that the assessments presented in this series are insensitive to even large changes in $\lambda . D_{i j}$ is the distance from the veteran's $i$ th known location to the $j$ th coordinate in the herbicide spray file. For an individual veteran, the expression in Eq. (1) is integrated mathematically from $t=t_{1, i j}$ to $t=t_{2, \mathrm{ij}}$, where $t_{1, i j}$ is the first date he was stationed at location $i$, and $t_{2, \mathrm{ij}}$ is the date he left it. The integral is evaluated for each location $j$ in the spray file which falls within $15 \mathrm{~km}$ of veteran location $i$, provided herbicide spraying occurred prior to $t_{2, i j}$. If the spraying occurred after time $t_{1, i j}$, then the lower limit of the integral is set to the actual date of spraying. This index thus counts all sprayings which ever occurred near each location reported by the veteran, weighted inversely according to distance (i.e., higher weighting to closer distances), exponentially according to elapsed time (i.e., higher weighting to more recent sprayings). The data used in construction of this index are, of course, derived from respondents' self-reports of locations in Vietnam, and, as such are subject to recall error. Nevertheless, subjects appear to have exercised considerable care filling out this portion of the survey.

Although three major herbicides (and several other minor ones) are listed in the file, public and professional attention has centered on Agent Orange, a 1:1 mixture of the $n$-butyl esters of 2,4-D and 2,4,5-T. Agent White also contained 2,4-D, while Blue consisted of an organic arsenic compound (cacodylic acid). It has been suggested by some that only Agent Orange is of health interest, because the 
2,4,5-T is most likely to have been the source of TCDD contamination. A recent study linking 2,4-D usage to increases in non-Hodgkins lymphoma in Kansas farmers (Hoar et al., 1986) strongly suggests that 2,4-D exposure may be important as well.

We initially calculated two indices for each subject. One index, designated OE3, uses Eq. (1) but only utilizes Agent Orange spray file records. The second index, AE3, also uses Eq. (1) but utilizes all the spray records on the tape. OE3 and AE3 are highly correlated, with a correlation coefficient $r=0.88$. Virtually all the results obtained in our analyses are reached whether OE3 or AE3 is used. The results here will be presented based upon the Agent Orange exposure index, OE3.

The survey also posed a set of questions which dealt with whether the respondent had ever handled herbicides and/or had carried out the following jobs that entailed working with herbicides: a sprayer on a C-123, a sprayer on a helicopter, a sprayer on a boat, been a herbicide loader or handler during shipment, had been a herbicide storage handler, or had participated in Operation Ranchhand. There were 102 study subjects who fell into one or another of these categories. For purposes of herbicide exposure categorization these men are labeled "herbicide handlers" and are usually considered as a separate group.

\section{Combat Exposure Measures}

The survey instrument included a series of eight questions which sought to characterize the extent to which respondents had undergone traumatic combat experiences. The questions, which queried the extent of enemy fire and lifethreatening situational exposures, were designed to be compatible with other studies on combat-related effects on Vietnam veterans (Frye and Stockton, 1982; Figley, 1978; Roberts et al., 1982) and together formed a highly reliable index (Cronbach $\alpha=0.96$ ), with a possible score ranging from 8 to 40 . The items constituting the combat scale are given in Table 1 .

\section{RESULTS}

\section{Herbicide Usage in Vietnam}

Figure 1 shows the total number of gallons of each of the three herbicides, and number of missions in which spraying occurred in Vietnam, classified according

TABLE 1

\section{Items Constituting the Combat Scale}

\footnotetext{
"During your service in the armed forces, how often did you experience the following:"

Responses: "Never" = 1, "Rarely" = 2, "Sometimes" = 3, "Often" = 4, "Very often" =

a. Fire your weapon at the enemy?

b. Kill the enemy?

c. See someone killed?

d. See the enemy wounded?

e. See our guys wounded?

f. See dead enemy?

g. See our dead?

h. Find yourself in a situation you thought you would never survive?
} 
a

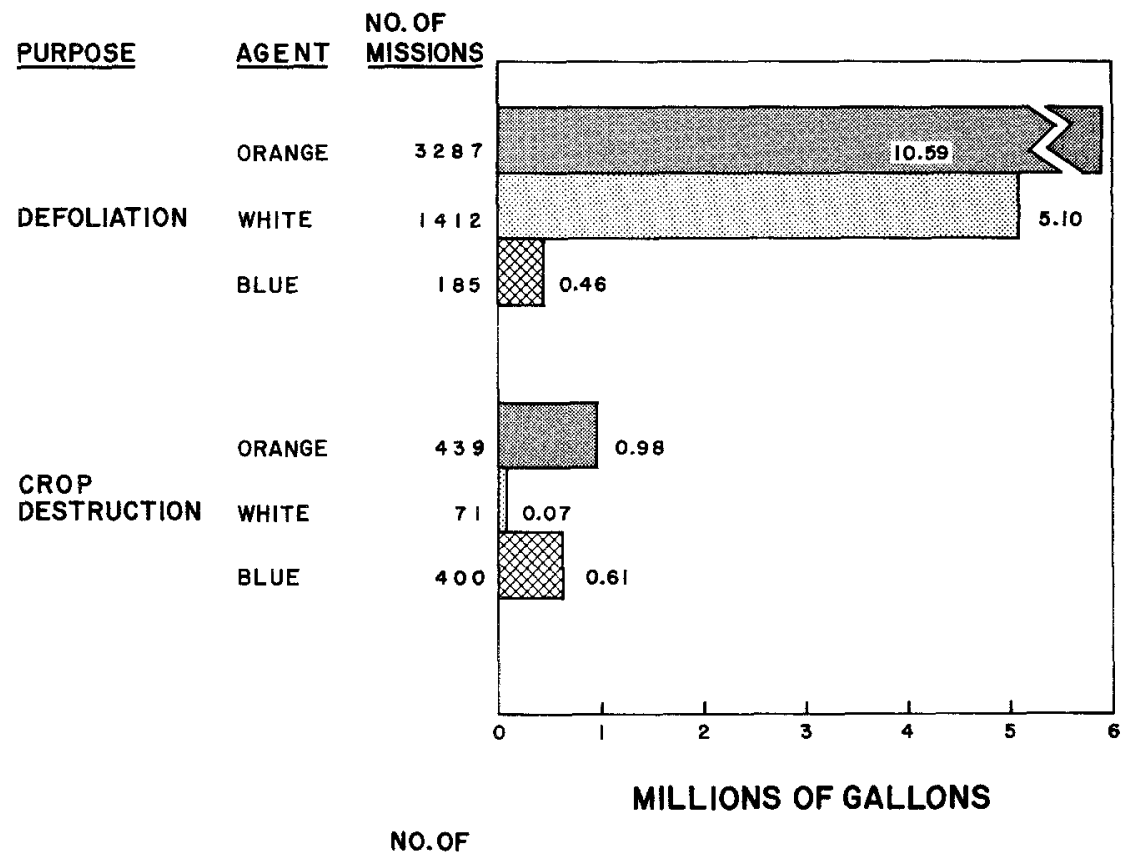

\begin{tabular}{|c|c|}
\hline PURPOSE & AGENT \\
\hline BASE PERIMETERS & $\begin{array}{l}\text { ORANGE } \\
\text { WHITE } \\
\text { BLUE }\end{array}$ \\
\hline $\begin{array}{c}\text { ENEMY CACHE } \\
\text { SITES }\end{array}$ & $\begin{array}{l}\text { ORANGE } \\
\text { WHITE } \\
\text { BLUE }\end{array}$ \\
\hline WATERWAYS & $\begin{array}{l}\text { ORANGE } \\
\text { WHITE } \\
\text { BLUE }\end{array}$ \\
\hline $\begin{array}{l}\text { COMMUNICATION } \\
\text { LINES }\end{array}$ & $\begin{array}{l}\text { ORANGE } \\
\text { WHITE } \\
\text { BLUE }\end{array}$ \\
\hline $\begin{array}{c}\text { ENEMY SUPPLY } \\
\text { ROUTES }\end{array}$ & $\begin{array}{l}\text { ORANGE } \\
\text { WHITE } \\
\text { BLUE }\end{array}$ \\
\hline
\end{tabular}

No.OF

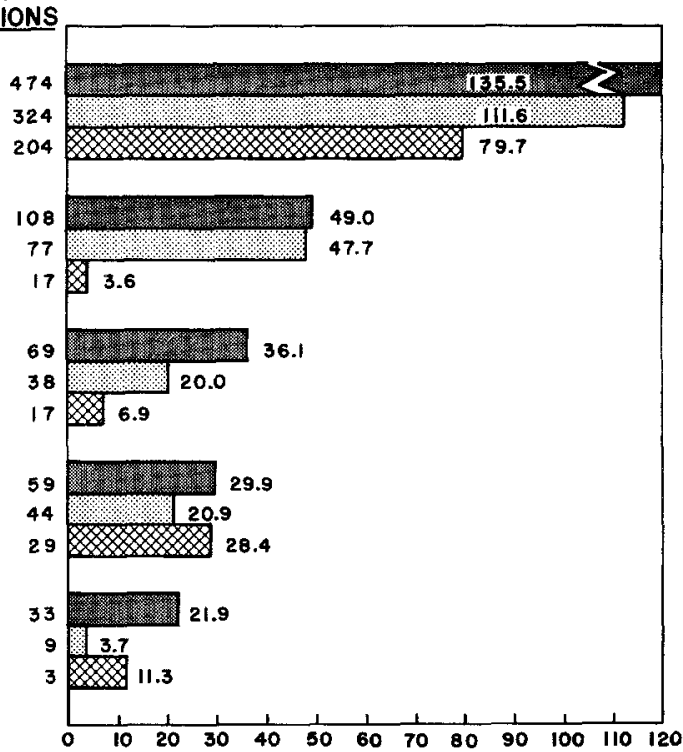

THOUSANDS OF GALLONS

FIG. 1. Quantities of Agents Orange, White, and Blue used in South Vietnam, 1965-1971, by type of missions. (a) Defoliation and crop destruction missions. (b) Five minor types of missions.

to the type of mission. Defoliation of jungle constituted the most important herbicide use, but a significant amount (in the millions of gallons) was used in programs to destroy food crops (Fig. 1a); lesser amounts (in the thousands of gallons) were also used to clear communication lines, waterways, and base camp perim- 
eters (Fig. 1b). The termination of the spraying programs did not come abruptly, but tapered off in 1970-1971, Figure 2 shows the total number of gallons of herbicide applied, by agent, for each quarter beginning in 1965, when appreciable amounts began to be used. The precipitous drop during early 1968 corresponds to the Tet Offensive.

It is to be noted that over 1000 missions were for clearance of base perimeters. About half of these involved Agent Orange (about 135,000 gallons). While this quantity represents only a scant $1.1 \%$ of the 11.8 million gallons of Agent Orange sprayed in Vietnam, much of it was applied by individual servicemen using portable backpacks, directly on or adjacent to troop installations, and therefore, may contribute disproportionately to troop exposure when compared, for example, to spraying from $\mathrm{C}-123$ planes.

\section{Herbicide Exposures among the Study Population}

Herbicide exposure applies only to the 2858 study subjects who served in Southeast Asia. Of these men, 2387 (83.5\%) filled out the map section of the questionnaire, and $2087(87.4 \%)$ of those provided sufficient information on dates of service in the identified locations to allow quantification of herbicide exposure according to Eq. (1).

Overlaid on Fig. 2 is a histogram which shows the number of study subjects who were actually in Southeast Asia during the given period. It can be seen that those

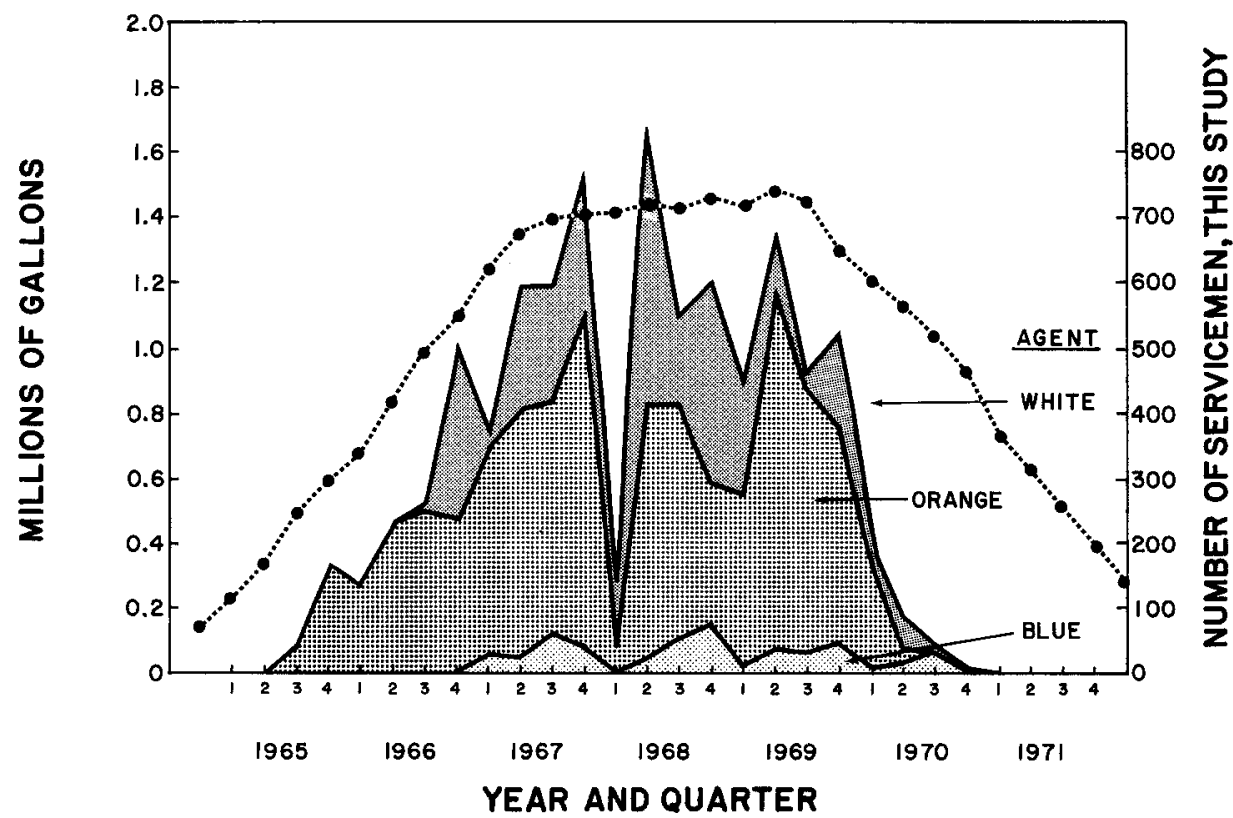

Fig. 2. Quantities of Agents Orange, White, and Blue used in South Vietnam, 1965-1971 (shaded areas), and number of study subjects stationed in South Vietnam (dotted line), by calendar quarter. 
Legionnaires who served in Southeast Asia tended to be there at times of the greatest spraying activity, and consequently might be expected to have had significant opportunities for exposure. As will be shown below, this turned out to be the case.

Figure 3 shows the distribution of the herbicide exposure index OE3. There were 162 subjects $(7.8 \%)$ with a score of exactly zero. The mean was 0.357 , median 0.117 , and standard deviation 0.752 . Ninety percent of OE3 scores were below 0.830 , but the distribution has a very long tail, extending to a high value of 9.905 for 1 subject.

One hundred two men in the study population reported having carried out duties that involved the direct handling of herbicides and 83 of them provided sufficient data on the exposure map for the OE3 index to be calculated. Their mean exposures are given in Table 2. While the OE3 indices of some of these handler groups are higher than the average for all Southeast Asia subjects (especially plane and helicopter sprayers), none of the group means differ significantly from the mean for all men who served in Southeast Asia. This is because the index is reflective of geographic location and not job. Many herbicide handlers appear to have been stationed in areas in Vietnam which received an "average" amount of herbicide spraying, although they themselves may have had much more intense exposures to the chemical agents during the course of their assigned duties. We thus consider the OE3 index to be an insufficient reflection of the complete exposures of herbicide handlers. Therefore, in most of the analyses in which herbicides are involved, the men whose jobs entailed the direct handling of herbicides were segregated from the rest of the study population and analyzed as a separate group.

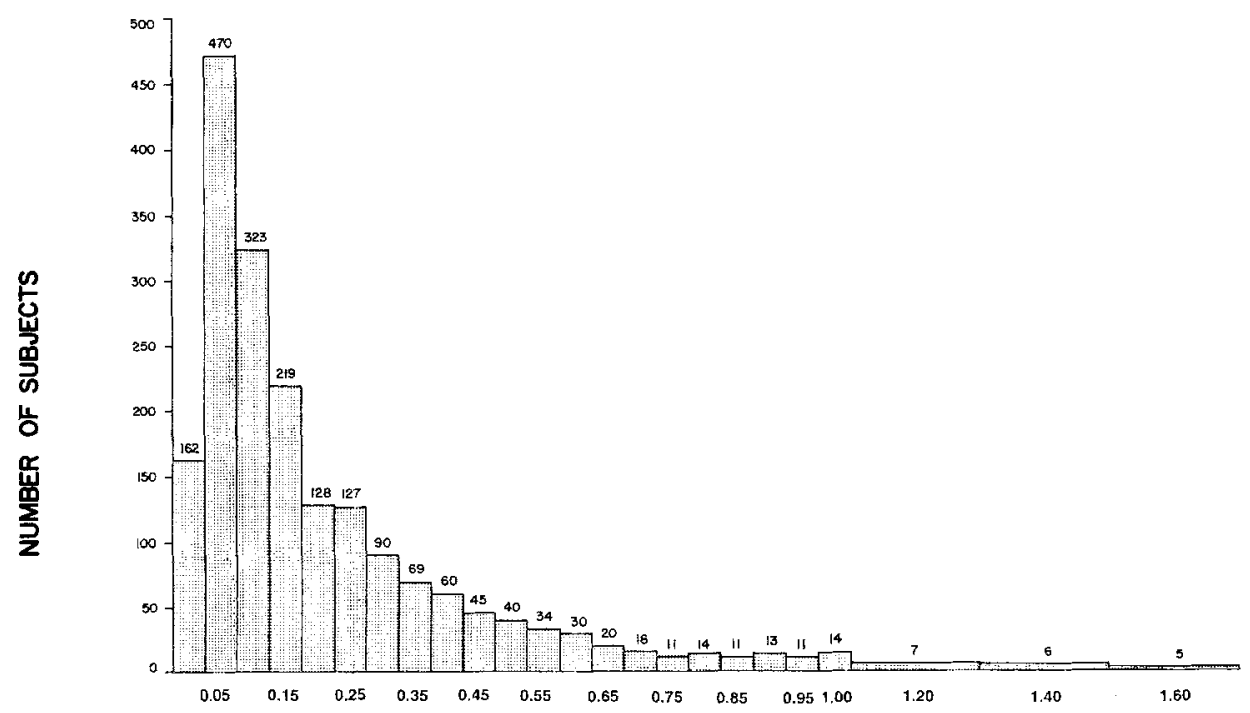

AGENT ORANGE EXPOSURE INDEX

FIG. 3. Frequency distribution of Agent Orange exposure index, OE3, among study subjects. 
TABLE 2

Mean Herbicide Exposure Indices among Those with Herbicide Contact Jobs

\begin{tabular}{lrll}
\hline \multicolumn{1}{c}{ Job } & $N$ & Mean & $\begin{array}{c}95 \% \text { Confidence } \\
\text { intervals }\end{array}$ \\
\hline All SEA & \multicolumn{1}{c}{$N$} & 0.357 & $0.32-0.39$ \\
Handled herbicides & 83 & 0.45 & $0.27-0.62$ \\
Sprayer: C-123 & 11 & 0.55 & $0.08-1.03$ \\
Helicopter & 22 & 0.88 & $0.32-1.44$ \\
Boat & 3 & 0.2 & $0 .-0.56$ \\
Loader handler & 21 & 0.38 & $0.10-0.65$ \\
Storage handler & 33 & 0.32 & $0.14-0.49$ \\
Ranchhand & 25 & 0.32 & $0.14-0.50$ \\
\hline
\end{tabular}

\section{Exposure to Combat}

The level of combat was evaluated for each subject, using the scale items described in Table 1. The distribution of combat scores among men who served in Southeast Asia is contrasted with those of men who served elsewhere in Fig. 4. Combat was also categorized into three levels, as shown in Table 3. Two-fifths of Southeast Asia veterans had combat scores of 8 to 15, inclusive, and are designated "low" combat. Another two-fifths had scores of 16 to 25 , inclusive, and are designated "medium" combat. The remaining one-fifth are called "high" combat.

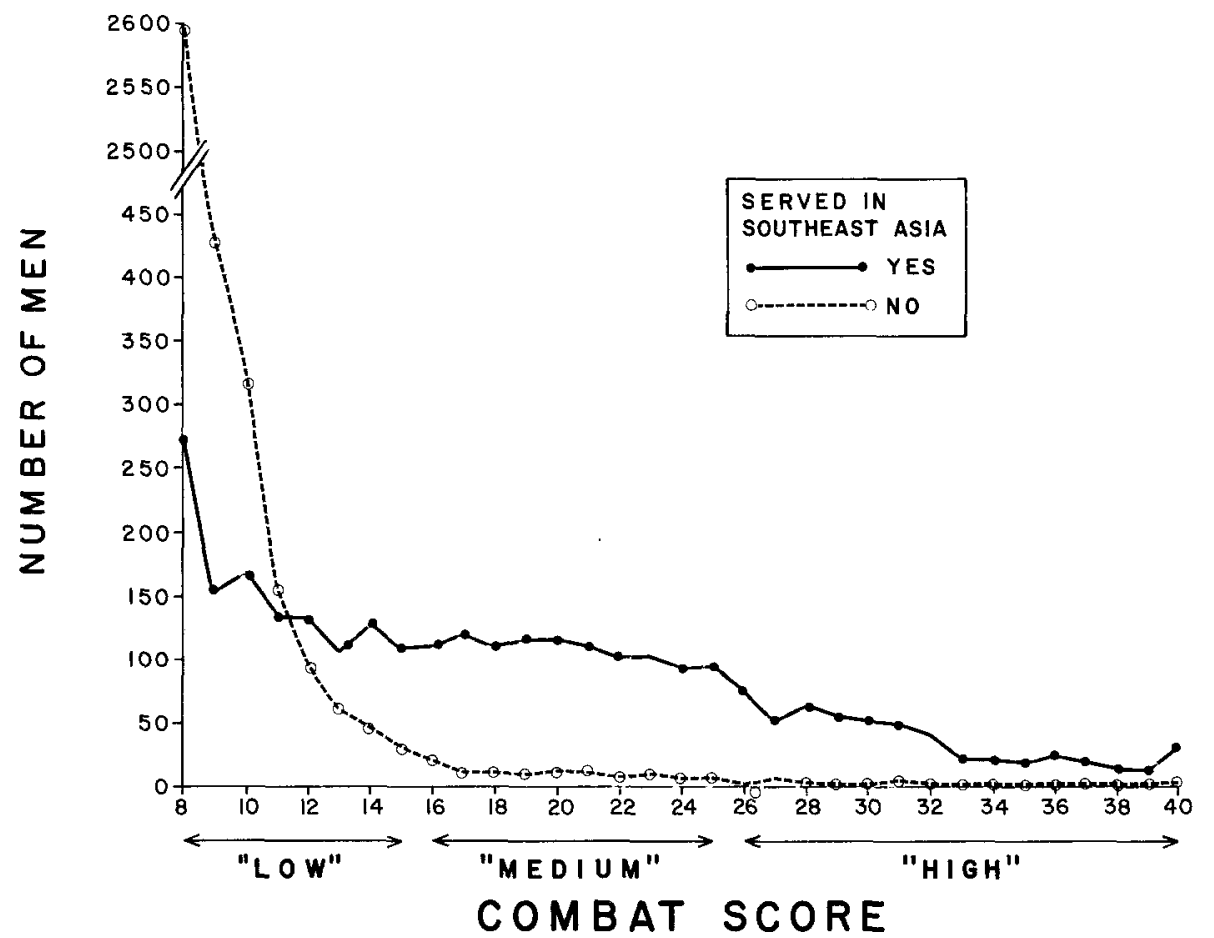

FIG. 4. Frequency distribution of combat scores among study subjects according to location of military service: Southeast Asia (solid line) and elsewhere (dashed line). 
TABLE 3

Percentage Distribution of Combat Scores According to Area Served

\begin{tabular}{|c|c|c|}
\hline Level of combat & $\begin{array}{c}\text { Served in } \\
\text { Southeast Asia }\end{array}$ & $\begin{array}{l}\text { Served } \\
\text { elsewhere }\end{array}$ \\
\hline & \multicolumn{2}{|c|}{ Percentage } \\
\hline $8-10$ & $20.9 \%$ & $86.4 \%$ \\
\hline $11-15$ & 21.6 & 10.1 \\
\hline $16-20$ & 20.3 & 1.6 \\
\hline $21-25$ & 17.8 & 1.0 \\
\hline $26-40$ & 19.4 & 0.9 \\
\hline Total & $100.0 \%$ & $100.0 \%$ \\
\hline No. subjects & 2845 & 3863 \\
\hline
\end{tabular}

As can be seen, the great majority of non-Southeast Asia veterans (96.5\%) had low exposure to combat.

The extent of combat experienced by troops in Vietnam was related to the branch of the armed services in which they served, as shown in Fig. 5. Fifty-seven percent of the men who served in the Marines and $44.4 \%$ of those in the Army scored in the two highest levels of the combat measure, while only $16 \%$ and $14.7 \%$ of those in the Navy and Air Force, respectively, reported such intense combat experiences.

\section{Relationship between Combat and Herbicide Exposure}

Combat experience and Agent Orange exposure are related, as shown in Fig. 6. The mean OE3 scores were significantly higher for men in high combat areas than for men in either medium or low combat areas. The average exposure to Agent

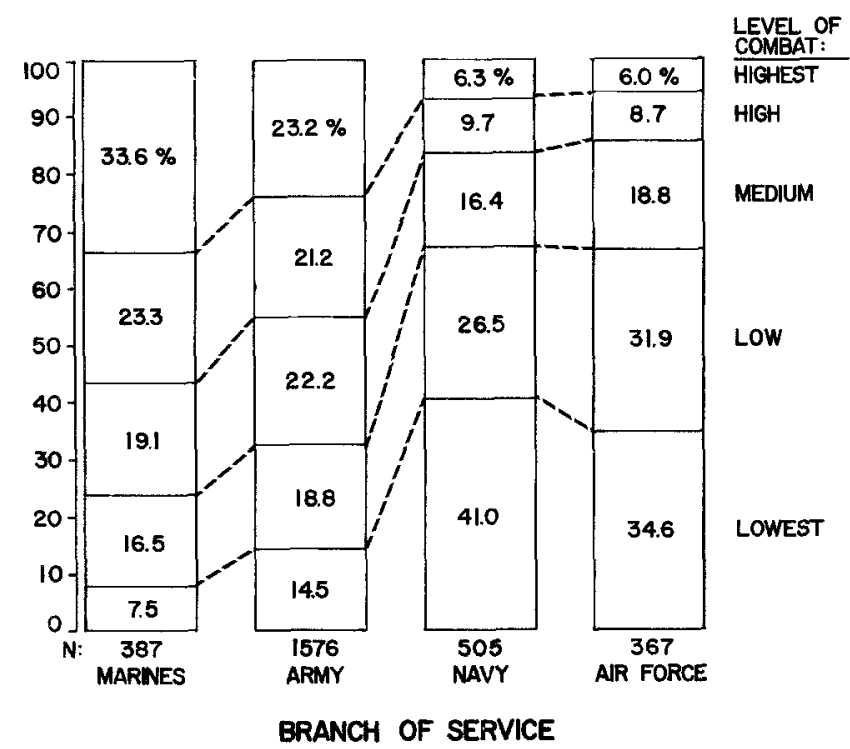

FIG. 5. Percentage distribution of combat scores of men who served in Southeast Asia, according to branch of service. 


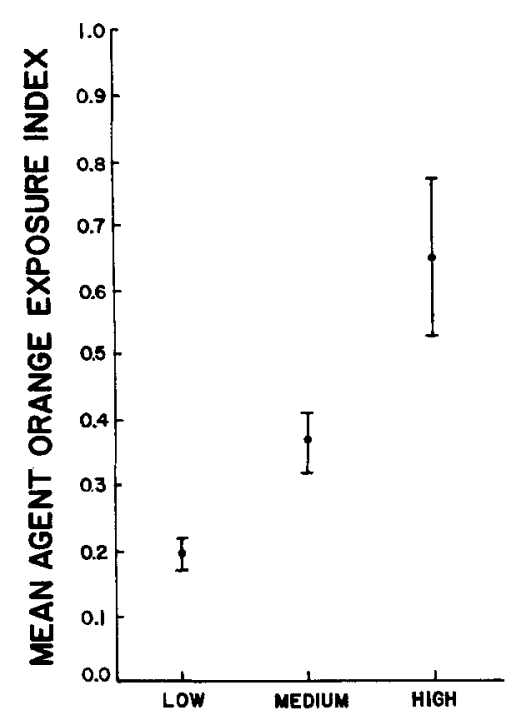

Level of Combat in Southeast Asia

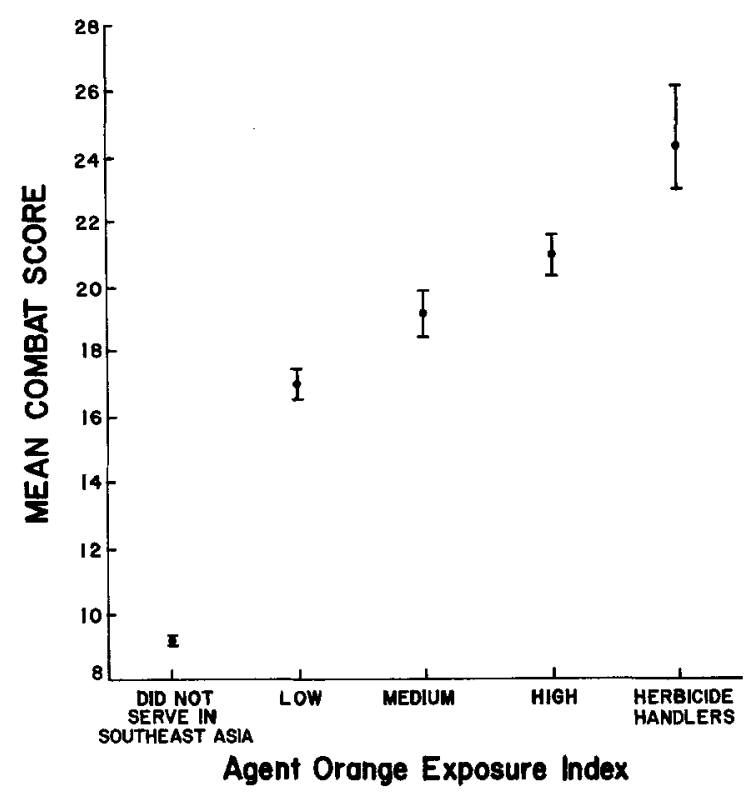

Agent Orange Exposure Index

FIG. 6. (Left) Mean Agent Orange score classified by categorical level of combat. (Right) Mean combat score classified by categorical level of Agent Orange exposure, with herbicide handlers considered separately. Vertical bars represent $95 \%$ confidence intervals about the mean.

Orange among high combat subjects was about three times that for low combat subjects. Figure 6 also shows the direct increase in mean combat level with increasing level of OE3 index, and also shows highest combat levels among men with herbicide jobs. The mean combat score differed significantly among these groups. Herbicide handlers had the highest mean combat scores, about $50 \%$ higher than those with the lowest Agent Orange index OE3.

\section{DISCUSSION}

The data presented here once again confirm the massive use of herbicidal agents in Vietnam, primarily for defoliation purposes. They also graphically demonstrate the overlay between the use of the herbicides and the combat activities of significant segments of the armed services serving in Vietnam.

We, of course, realize that the classification of exposure to herbicides of Vietnam veterans is fraught with controversy and we have addressed these methodological issues previously (Stellman and Stellman, 1986). All component dates for an individual veteran were edited for consistency with his stated dates of military service and service within Southeast Asia. This makes it extremely unlikely that an individual even having access to the updated HERBS tape and our published algorithm could deliberately fabricate a high or low score for himself. Additionally, all questionnaires were completed before our methodology was in print.

A second issue has been the possibility of inaccuracy and incompleteness of the HERBS tape itself and, hence, its adequacy as the primary source of exposure information. The HERBS tape has undergone extensive and continual revision by a highly sophisticated group within the armed services. The revision has included 
the reexamination of thousands of records, reflecting the daily logs of troop movements in Vietnam. These data are contained in hundreds of reels of tape and represent the most complete records of any military conflict in history.

Despite constant checking and updating, some records may still be incomplete or erroneous. Even allowing a reasonable margin of error in the data, the HERBS tapes still provide precise, detailed information on the distribution of nearly 19 million gallons of herbicide. In fact, if we compare the exposure measures used in any of the studies cited in this series, or in occupational epidemiology, or in other areas of chronic disease epidemiology, excluding clinical measures (which have their own shortcomings), the HERBS tapes fare very well as a source of exposure classification.

\section{Possible Sources of Bias in the American Legion Study}

There are, of course, obvious limitations to the methods used in the present study. Some derive from the cross-sectional, self-reported nature of the design, others from possible inaccuracies in reporting time and place of service in Vietnam. We have discussed some of these limitations in exposure assessment in our previous report (Stellman and Stellman, 1986).

There are two major selection issues to be considered: bias and representativeness. All comparisons in this report are internal to the sample at hand. While use of internal comparisons never guarantees absence of bias, it is a powerful method for minimizing systematic errors.

Representativeness of study subjects is intimately related to their response rates, defined here as the number of questionnaires received, divided by the number mailed out, excluding those returned for bad addresses or otherwise undeliverable. In the present study return rates ranged from a low of $52.5 \%$ in Pennsylvania to a high of $64.1 \%$ in Minnesota. Questions concerning representativeness and bias hinge on whether subjects who did not return a questionnaire would have given responses similar to those actually received. If, for instance, the reason for nonresponse was related to health, many of the results presented in the health effects paper of this series would be biased.

We addressed the question of representativeness by examining patterns of responses to key questions within different subgroups who can be identified within areas of high or low response internal to the sample.

Every American Legionnaire belongs to a Post. We tabulated the response rate for every Post which had at least one member to whom a questionnaire was mailed. Table 4 shows the distribution of response rates within the Minnesota and Pennsylvania Departments. It shows, for example, that $24.8 \%$ of the subjects who responded from Minnesota belong to American Legion Posts which collectively enjoyed a response rate about $80 \%$. In contrast, only $15.3 \%$ of the Pennsylvania subjects in the study came from Posts with an $80 \%$ response rate or higher. Note that the table contains counts of individuals, not the Posts themselves.

The critical question is whether the distribution of important variables differs between men coming from high-response Posts, compared with men from lowresponse Posts. We examined the relevant distributions of many variables and found no differences that could have affected the study results materially. For 
TABLE 4

Distribution of Response Rates among American Legion Members Belonging to Posts in Minnesota and Pennsylvania

\begin{tabular}{ccc}
\hline Post response rate & Minnesota & Pennsylvania \\
\hline Below $20 \%$ & $5(0.3)$ & $23(1.4)$ \\
$20.1 \%$ to $40 \%$ & $59(3.4)$ & $207(12.5)$ \\
$40.1 \%$ to $60 \%$ & $451(26.0)$ & $653(39.6)$ \\
$60.1 \%$ to $80 \%$ & $789(45.5)$ & $516(31.3)$ \\
Above $80 \%$ & $429(24.8)$ & $252(15.3)$ \\
Total & $1733(100.0 \%)$ & $1651(100.0 \%)$ \\
\hline
\end{tabular}

instance, the percentage of men who served in Southeast Asia was not significantly different among men from high-response Posts compared with men from low-response Posts $(P>0.05)$. There were also no significant differences between high-response and low-response subjects with respect to education, income, or reason for joining The American Legion.

General health did differ significantly between men from Posts with high and low response, but this difference was due entirely to the distinction between "Excellent" and "Good" health. Among high response subjects (from Posts with over two-thirds response rates) in Pennsylvania, 36.9\% rated their health "excellent" and $52.3 \%$ rated it "good". This compares to 28.2 and $59.2 \%$, respectively, in low-response men from Posts where 50\% or fewer returned their questionnaires. Age was also related to response rate, with the younger subjects more likely to return the questionnaires.

Most importantly, neither analysis of variance nor regression revealed significant differences between high and low response subjects with respect to combat score or Agent Orange exposure index. Table 5 shows the distribution of categorized Agent Orange exposure scores (low, medium, high) among Minnesota and Pennsylvania subjects according to the response rates of their Posts. These distributions are practically identical for subjects who belonged to low-response Posts and those who belonged to high-response Posts, and give us confidence that there is little response bias in our study population with respect to herbicide exposure.

As a final tool for assessing possible bias, we asked the respondents to provide

TABLE 5

Distribution of Agent Orange Exposure Index (OE3) among Study Subjects, According to Overall Response Rate of Their american Legion Posts

\begin{tabular}{lccc} 
& \multicolumn{3}{c}{ Post response rates } \\
\cline { 2 - 4 } & Up to $50 \%$ & 51 to $66 \%$ & 67 to $100 \%$ \\
\hline Agent Orange exposure index & 40.9 & Percentage & \\
Low & 32.0 & 41.2 & 41.8 \\
Medium & 27.1 & 29.4 & 29.8 \\
High & 100.0 & 29.4 & 28.4 \\
Total & 100.0 & 100.0 \\
\hline
\end{tabular}


the "best" reason that they had for joining The American Legion. These answers are tabulated in Table 6. The men who served in Southeast Asia and the men serving elsewhere had a similar distribution of "best" reasons for joining The Legion. Most people joined through their social network, either by being recruited by a family member or a friend or acquaintance. About $17 \%$ joined because the Legion represented a good place to socialize, and about an equal percentage joined for patriotic reasons. Of particular importance here is that only about $1 \%$ stated that they had joined because they had a special "problem" for which they needed Legion assistance. This observation effectively removes membership selection as a possible source of bias.

\section{Epidemiological Adequacy of Exposure Methodology}

The quantified exposure probabilities presented here are applicable at the level of the individual, and are to be used as measures in epidemiologic analyses in the papers that follow. We suggest that our method, or its equivalent, can be profitably used in most epidemiologic studies of the effects of herbicides on U.S. troops. Our data, supplied by nearly 2100 study subjects with Vietnam experience, when combined with information from historical military records, not only provide quantitative evidence of the concomitant buildup and movement of troops alongside herbicide spray operations (Fig. 2), but also make the convincing point that sufficient numbers of troops are available and identifiable for epidemiologic study of herbicide effects.

This conclusion is also based on two further observations. The first is that the distributions of herbicide exposures (Fig. 3) show a large proportion of men whose likelihood of exposure was either nil or low, while a sizeable number of individuals were classified as "high" exposure, either because of a high numerical exposure index, or because their military duties involved direct handling of herbicides. The second observation is that health-related effects to be presented in the successor papers of this series often display a dose-response relationship with respect to herbicide exposure. In addition, the health outcomes which display

TABLE 6

Best Reason Given for Jolning The American Legion, by Area Served

\begin{tabular}{lcc}
\hline & $\begin{array}{c}\text { Served in } \\
\text { Southeast Asia }\end{array}$ & Served elsewhere \\
\hline $\begin{array}{l}\text { Someone in my family was a member and encouraged me } \\
\text { to join. }\end{array}$ & 25.2 & 23.9 \\
$\begin{array}{l}\text { The American Legion is a good place to socialize in } \\
\text { my town (e.g., have a drink on the weekend). }\end{array}$ & 16.5 & 17.7 \\
I was recruited by a friend or acquaintance. & 34.6 & 35.3 \\
I had some personal problems (such as with the VA) & 1.2 & 0.9 \\
$\quad$ and I joined The Legion to help me work them out. & 18.0 & 18.6 \\
I joined for patriotic reasons. & 4.5 & 3.6 \\
Other reasons. & & \\
\hline
\end{tabular}


such relationships are specific and consistent with those observed in clinical, experimental, and other epidemiological studies.

The availability of a readily used and inexpensive exposure classification system (in contrast to invasive, expensive, and yet to be validated exposure methods such as analysis of dioxin residues in tissue collected some 15 years postexposure) is encouraging for future studies. Both the accuracy and precision of the method are comparable to, or exceed, those used in many major environmental and occupational studies. The combination of reliable combat intensity exposure scales and exposure methods, such as used here, should help other investigations elucidate further the effects of the Vietnam experience on Vietnam veterans.

\section{ACKNOWLEDGMENTS}

We thank the following individuals for the invaluable contributions which they made to this project. Lawrence Garfinkel, American Cancer Society, for generous support and encouragement; Richard Christian, U.S. Army Joint Services Environmental Support Group for advice and comments; Dr. Gloria Gordon for conducting the pretest; Charles English for quality control and programming services; Erroll Sinclair for data management; Andrew Stellman for graphical and other computer support; Luz Tejeiro and Joe Buardo for graphics; Robert Slaymaker for word processing services; and the hundreds of American Legion volunteers who cared enough to devote their time and service to make this project a success.

\section{REFERENCES}

Boulanger, G., and Kadushin, C. (Eds.). (1986). "The Vietnam Veteran Redefined: Fact and Fiction." Erlbaum, Hillsdale, NJ.

DiDomenico, A., Silano, V., Viviano, G., and Zapponi, G. (1980). Accidental release of 2,3,7,8tetrachlorodibenzo-p-dioxin (TCDD) at Seveso, Italy. V. Environmental persistence of TCDD in soil. Ecotoxicol. Environ. Safety 4, 339-345.

Egendorf, A. (1985). "Healing from the War: Trauma and Transformation after Vietnam." Shambala, Boston.

Figley, C. R. (1978). Psychosocial adjustment among Vietnam veterans, In "Stress Disorders Among Vietnam Veterans." (C. R. Figley, Ed.). Brunner/Mazel, New York.

Fischer, V., Boyle, J. M., Bucuvalas, M., and Schulman, M. A. (1980). "Myths and Realities: A Study of Attitudes Toward Vietnam Era Veterans." Louis Harris and Associates, Inc., Washington, $\mathrm{DC}$.

Frye, J. S., and Stockton, R. A. (1982). Discriminant analysis of posttraumatic stress disorder among a group of Vietnam veterans. Amer. J. Psychiatry 139, 52-56.

Gough, M. (1986). Dioxin. “Dioxin, Agent Orange: The Facts." Plenum, New York.

Hoar, S. K., Blair, A., Holmes, F. F., Boysen, C. D., Robel, R. J., Hoover, R., and Fraumeni, J. F., Jr. (1986). Agricultural herbicide use and risk of lymphoma and soft-tissue sarcoma. J. Amer. Med. Assoc. 256, 1141-1147.

Kearny, P. C., Woolson, E. A., and Ellington, C. P., Jr. (1972). Persistence and metabolism of chlorodioxins in soils. Environ. Sci. Technol. 6, 1017-1019.

Roberts, W. R., Penk, W. E., Gearing, M. L., Robinowitz, R., Dolan, M. P., and Patterson, C. T. (1982). Interpersonal problems of Vietnam combat veterans with symptoms of posttraumatic stress disorder. J. Abnorm. Psychol. 91, 444-450.

Snow, B. R., Stellman, J. M., Stellman, S. D., and Sommer, J. F., Jr. (1988). Posttraumatic stress disorder among American Legionnaires in relation to combat experience in Vietnam: Associated and contributing factors. Environ Res. 47, 175-192.

Stellman, S. D., and Stellman, J. M. (1986). Estimation of exposure to Agent Orange and other defoliants among American troops in Vietnam: A methodological approach. Amer. J. Ind. Med. 9, 305-321. 
Stellman, J. M., Stellman, S. D., and Sommer, J. F., Jr. (1988a). Social and behavioral consequences of the Vietnam experience among American Legionnaires. Environ. Res. 47, 129-149.

Stellman, S. D., Stellman, J. M., and Sommer, J. F., Jr. (1988b). Health and reproductive outcomes among American Legionnaires in relation to combat and herbicide exposure in Vietnam. Environ. Res. 47, 150-174.

Stellman, J. M., Stellman, S. D., and Sommer, J. F., Jr. (1988c). Utilization, attitudes, and experiences of Vietnam Era veterans with Veterans Administration health facilities: The American Legion experience. Environ. Res. 47, 193-209.

U.S. Army Joint Services Environmental Support Group (1986). "Services HERBS Tape-A Record of Helicopter and Ground Spraying Missions, Aborts, Leaks, and Incidents." Department of the Army, Washington, DC.

Young, A. L., Thalken, C. E., Arnold, E. L., Cupello, J. M., and Cockerham, L. G. (1976). "Fate of 2,3,7,8-Tetrachlorodibenzo-p-Dioxin (TCDD) in the Environment: Summary and Decontamination Recommendations (USAFA-TR-76-18)." Department of Chemistry and Biological Sciences, U.S. Air Force Academy, CO. 